TABLE IV.-Dcath Rate in Rolation to Type Incidence, Edinburgh, 192.9-30.

\begin{tabular}{cccc|c|c|c}
\hline \multicolumn{3}{c}{ T: ps. } & & No. of Cases. & No. of Deaths. & $\begin{array}{c}\text { Drath Rate } \\
\text { (Percentage). }\end{array}$ \\
\hline I & $\ldots$ & $\ldots$ & $\ldots$ & 53 & 12 & 23 \\
II & $\ldots$ & $\ldots$ & $\ldots$ & 75 & 23 & 31 \\
III & $\ldots$ & $\ldots$ & $\ldots$ & 7 & 5 & 71 \\
IV & $\ldots$ & $\ldots$ & $\ldots$ & 47 & 5 & 10 \\
\hline
\end{tabular}

It is to be observed that the order of severity is similar to that of other workers. The numbers, of course, are small, and may be insufficient for an exact statistical statement, but it is interesting to note that the death rate in Group IV is as low as 10 per cent.

Summary.

1. A brief review of the incidence of the different types of pneumococci in tobar preumomia according to a number of observers from 1913 to date is given.

2. The incidence of pneumococcus types in 186 patients suffering from acute lobar pneumonia in Edinburgh during the past eighteen months is recorded, and also the mortality rates associated with the different types.

The authors gratefully acknowledge facilities granted to them by the physicians to the Royal Infirmary, Edinburgh, and thank Professor T. J. Mackie for valuable assistance. The expenses of this work were met in part by a grant from the Moray Fund Edinburgh University. One of us (J. M. A.) was in receipt of a grant from the Medical Research Council. Bibliography.

Bullowa, J. G. M.: Personal communication.
Cecil. R. L., Baldwin, H. S., and Larsen, N. P. : Arch. Int. Med., 1927, Cecil, R. $\mathrm{L}$

Christensen, S. : Commun. de l'Inst. Sérothérap., Copenhagen, 1923, גiv. Cooper, G.. Edwards, M., and Rosenstein, C. : Journ. Exper. Metl., 1929, xlix, 461.

avidson, L. S. P. : Proc Edin, Med.-Chir. Soc, Edinburglt Medical Journal, 1925, xxxii, 67.

Dochez, A. R., and Gillespie, L. J. Journ. Amer. Med. Assoc., 1913, Ixi, Ferguson, F. R., and Lovell, R. : Quart. Journ. of Mfd.. 19r8 x xii, 7x.

Glynn, E. E., and Digby, L.: Special Report Series, Medical R'scarch Griffith, F.: Journ. Hyg. Camb., 1928, xxvii, 113. ister, $F$. S. Published by the South African Institute of Medical Research, 1917, 10.

Malone, R. H. : Indian Journ. of Med. Research, 1925, xii. 565.

McLachlan, D. G. S. : Journ. Roy. San. Inst, 1925 , xlvi, 112

Schorer, E. H.: New York Mer. journ., 1919, ex, 97.

Stewart, D., and Gibson, II. J.: Élinbirgh Medical Journal, 1929, xxxvi, 607.

Thjötta, T., and Hanneborg, D.: Journ. Infect Dis., 1924, xxxiv, 454

\section{A CASE OF OSTEOGENESIS IMPERFECTA.} BY

J. E. WRIGHT, F.R.C.S.ED.,

MEDICAL SUPERINTENDENT, HOLBERTON HOSPITAL, ANTIGUA.

I. M., aged 34, a coloured woman, was admitted to the Holberton Hospital on July 3rd with a fracture of the left radius just below the insertion of the pronator teres, and a fracture of the right olecranon. Both fractures which seems to suggest that the pain was not of a degree usually associated with fractures even in an infant. Her first recollection was of a fractured femur, which was followed by many fractures of the lower limbs up to the age of 16 . These frequentry occurred at school, if she fell or was pushed about by other children. She stated that the fractures were painful, and used to swell.

According to the hospital records, she was admitted in 1904 at the age of 7 , with a fractured femur, and was in hospital from May 2nd to June 13th. The following year she was again
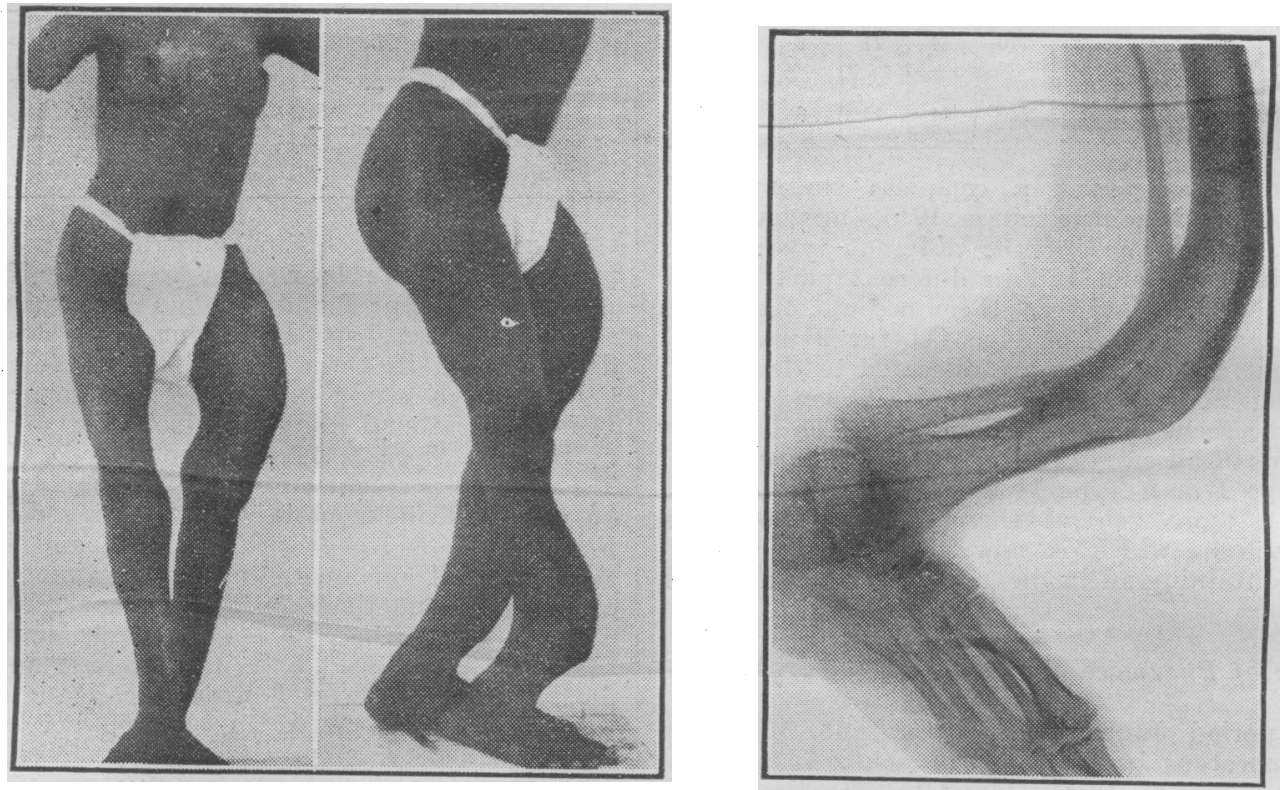

were the result of direct violence-by being beaten with a walking-stick. She was unaware that the olecranon was fractured, and complained only of the left arm, which she kneww was broken, and a contusion of the left leg. Her complaints of pain in view of pending legal proceedings were not very convincing, as she showed little sign of distress on manipulation. There was also a remarkable absence of swelling, ecchymosis, or muscular spasm.

Family History.

The patient's father was a tailor, who died of senile decay three years ago. He had had no serious illnesses or fractures. Her mother, whose legs were deformed, died some years ago, probably from pneumonia. The mother's sister, thought to be in America, also had deformed lower limbs. $A$ sister and two brothers are normal.

\section{Patient's History.}

The patient's mother told her that her legs were broken many times when a baby before she was old enough to feel pain, in hospital, from March 27th to May 23rd, with a fractured femur. In 1909 she was in hospital from February 19th to March 11th, the diagnosis being fragilitas ossium. On this occasion fractures were not specifically mentioned, but in viev of the diagnosis and her good health in other respects, it is probable that she had a fracture on this occasion also. For some years she was an inmate of the poorhcuse, reserved for the destitute and very chronic cases. She did not at any time appear to have been destitute. From the age of 16 until the present time she had had no fractures.

Clinical Examination.

The only thing of note about the patient, apart from the deformities, was the blue colour of the sclerotics, which is very striking in a coloured person. Her height was $4 \mathrm{ft} .10 \mathrm{in}$., reduced by the shortening of the lower limbs. All the long bones of the lower limbs were grossly deformed, particularly the left femur, which was bowed forwards and outwards, and the right tibia and fibula bowed forwards and inwards-well shown in the accompanying photographs. The anterior superior spines 
more practically horizontal when the patient stood erect, and the amount of scoliosis was negligible. The pelvic measurements were: interspinous $7 \frac{1}{2}$ in., intercristal $8 \frac{1}{2}$ in., external conjugate $6 \frac{1}{4}$ in.

There were deformilies on three ribs. The fifth right and sixth and seventh left suggested old fractures, but of these the palient had no recollection. The skull showed no abnormality; the bitemporal and biparietal diameters were rather shorter than average.

The long interval from the age of 16 to 34, during which no fracture occurred to the patient's knowledge; indicates that the tendency to fracture had diminished, since the recent fractures were caused by blows of some violence with the stick the patient used to walk with. She walked about fairly well by the aid of a stick, and earned he: living as a washer, which involved standing a considerable part of the day.

\section{Pathology of the Condition.}

The disease tends to run in families in 15 to 20 per cent. of the cases, and is associated with a blue colour of the sclerotics, which was markedly present in the case reported.

The foetal type presents the disease in its severest form. If not actually stillborn, these infants rarely survive more than a few months. At birth many have multiple fractures of the long bones and ribs. The vault of the skull is simply a membranous sac, while the cartilage boncs of the base are affected to a lesser degree. In most cases death is due to the powerful uterine contractions during labour on a brain so inadequately protected. The bones may show signs of old fractures which took place during intrauterine life.

Rather less severe is the infantile type, which manifests itself soon after birth. Fractures occur with the most careful handling of the child, as in carrying it about. The membranous bones of the skull are so feebly developed that they feel like a " bag of bones." 'The skull is widened in the transverse diameter, owing to the cranial contents lacking their normal bony support, and shortened anteroposteriorly from incomplete development of the cartilage bones of the base, giving the head a hydrocephalic appearance.

Sometimes the appearance is delayed until adolescence is reached, and it is then described as osteogenesis imperfecta tarda, which shows itself by the frequency of fractures from trivial causes. In this type the skull is fairly well formed, except for the late closure of the fontanelles. The case under review would appear to fall within this class.

An adult type is also described, in which the tendency to fracture appears only later. This might be a mild form of the disease, possibly overlooked in earlier life, or in the nature of a relapse, if the disease is to be regarded as a failure in development. The deformity is carısed rather by multiple fractures with malunion; others may be partial or subperiosteal rather than the bending of softened bones, as in rickets, osteomalacia, and osteitis deformans. $X$ rays show evidence of old fractures in this case.

Except in the foetal type, most of the fractures and consequent deformity occur in the lower limbs. The tendency to fracture diminishes with age in those who survive. Fractures are less painful and ecchymosis is less marked than in the normal individual, usually uniting in normal time, but generally with deformity after repeated fractures. Some partial fractures may pass unnoticed, aggravating the deformity, particularly: where the alignment of the bones is already imperfect. Histologically the epiphyseal line is straight and the proliferation of cartilage cells normal, and the fault seems to lie primarily with the esteoblasts which have failed to develop. The preliminary stages of bone formation are laid down, but the process is arrested by the failure of the osteoblasts to complete the work of bune formation. The periosteum is thickencd, but cartilage cells in their capsules take the place of developed osteoblasts. The Haversian canals are replaced by a fatty marrow, resulting in a thin red and porous cortex of imperfectly formed bone.

\section{Treatment.}

No treatment has any apparent effect on the course of the disease. Special care should be taken at school. Fractures should be treated as they arise, with particular regard to correct anatomical alignment in reduction. The possibility of partial or subperiosteal fractures should always be borne in mind in these cases after any injury, however slight.

\section{Atlentoranda: \\ MEDICAL, SURGICAL, OBS'TETRICAL. \\ PARTURITION PER PERINEUM.}

WE wish to record the occurrence of what appears to bo a unique case in the history of perineal tears.

Mrs. B., 2-para, was attended in her home by the outdoor house-surgeon. The infant was born to the umbilicus before assistance arrived, labour having bon precipitate. The child (weight $7 \mathrm{llh} .2 \mathrm{oz}$.) was not born per vias naturales, but through an extensive perineal tear (see photograph reproduced herewith).

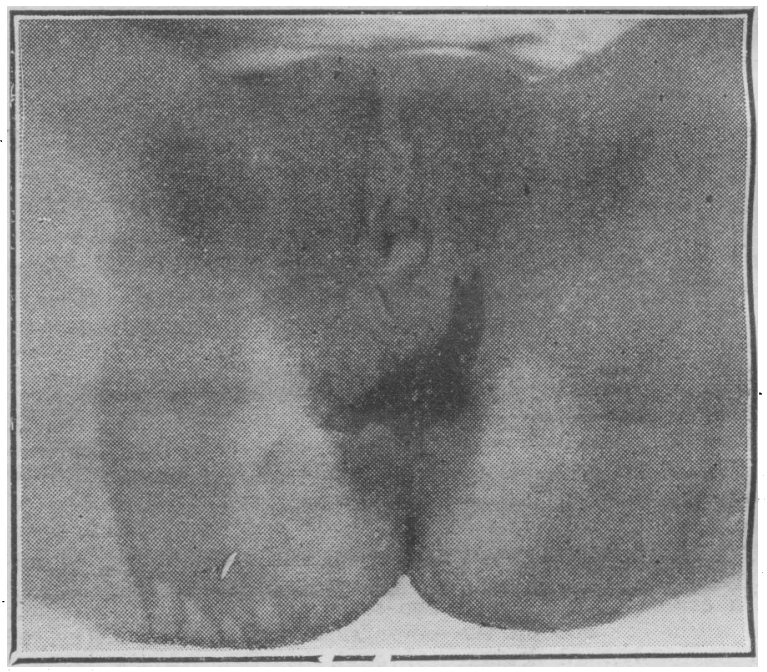

The tear was found to involve the posterior and lateral vaginal wall, the levator ani, and the transversus perinei. It extended laterally to the left two and a half inches from the central tendinous point of the perineum to the groove between the labium majus and the thigh, and to the right one inch from the same point. The anal sphincter was not involved, and there was very little haemorrhage.

The patient gave a history of having had an extensive tear at her previous confinement, which took place abroad. This possibly constituted a contributory factor.

We aesire to thank Professor James Hendry for giving us access to this case.

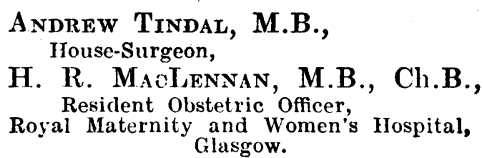
Glasgow.

\section{AN ABNORMAL LARGE INTESTINE WITH IMPERFECTLY DESCENDED OVARIES.}

The following case of arrested development of the large intestine, together with imperfect descent of the ovaries, is, I think, worthy of publication.

A girl, aged 15, was admitted to the Royal Hants County Hospital complaining of attacks of pain in the right side of her abdomen. A provisional diagnosis of recurring appendicitis was made.

At operation the right ovary was found lying in the iliac fown on a level with the anterior superior spine of the ilium. It was roighly cylindrical in shape, and posscssed a rectangular mesovarium a bout two inches square, springing from the peritoneum of the iliac 